\title{
Tuning PI Regulators for Three-Phase Induction Motor Space Vector Modulation Direct Torque Control Using Complex Transfer Function Concept
}

\author{
Alfeu J. Sguarezi Filho, José L. Azcue P. and Ernesto Ruppert \\ Additional information is available at the end of the chapter
}

http://dx.doi.org/10.5772/39006

\section{Introduction}

The dynamics of induction motor (IM) is traditionally represented by differential equations. The space-vector concept [13] is used in the mathematical representation of IM state variables such as voltage, current, and flux.

The concept of complex transfer function derives from the application of the Laplace transform to differential equations in which the complex coefficients are in accordance with the spiral vector theory which has been presented by [24]. The complex transfer function concept is applied to the three-phase induction motor mathematical model and the induction motor root locus was presented in [10]. Other procedures for modeling and simulating the three-phase induction motor dynamics using the complex transfer function concept are also presented in [4].

The induction machine high performance dynamics is achieved by the field orientation control (FOC) [1, 17]. The three-phase induction motor field orientation control using the complex transfer function concept to tune the PI controller by using the frequency-response function of the closed-loop complex transfer function of the controlled induction machine was presented in [2]. This strategy has satisfactory current response although stator currents had presented cross-coupling during the induction machine transients. An interesting solution was presented in [11] in which it was designed a stator-current controller using complex form. From this, the current controller structure employing single-complex zeros is synthesized with satisfactory high dynamic performance although low-speed tests had not been shown in mentioned strategies.

An alternative for induction motor drive is the direct torque control (DTC), which consists of the direct control of the stator flux magnitude $\lambda_{1}$ and the electromagnetic torque $T_{e}$. DTC controllers generate a stator voltage vector that allows quick torque response with the smallest 
variation of the stator flux. The principles of the DTC using hysteresis controllers and variable switching frequency have been presented by [22] and [6]. It has disadvantages such as low speed operation [19].

The PI-PID controllers are widely used in control process in industry [18]. The PI controller was applied to the IM direct torque control has been presented by [23]. Some investigations to tune the PI gains of speed controller have been presented using genetic-fuzzy [20] and neural networks [21]. These strategies have satisfactory torque and flux response although a method to tune the PI controllers for stator flux and electromagnetic torque loop and low-speed tests had not been shown.

To overcome low speed operation shortcomings, various approaches for DTC applying flux vector acceleration method $[9,14]$ and deadbeat controller $[5,12,15]$ have been reported. These strategies aim the induction motor control at low speed. In this case, the complex transfer function was not used to tune PI controllers for such strategy when the induction motor operates at any speed.

The aim of this book chapter is to provide the designing and tuning method for PI regulators, based on the three-phase induction motor mathematical model complex transfer function to be used in induction motor direct torque control when the machine operates at low speed which is a problem so far. This methods is in accordance with the present state of the art. The PI controller was designed and tuned by frequency-response function of the closed loop system. The controller also presents a minor complexity to induction motor direct torque control implementation. Experimental results are carried out to validate the controller design.

\section{The complex model of the induction motor}

The three-phase induction motor mathematical model in synchronous reference frame $(\mathrm{dq})$ is given by [16]

$$
\begin{gathered}
\vec{v}_{1 d q}=R_{1} \vec{i}_{1 d q}+\frac{d \vec{\lambda}_{1 d q}}{d t}+j \omega_{1} \vec{\lambda}_{1 d q} \\
0=R_{2} \vec{i}_{2 d q}+\frac{d \vec{\lambda}_{2 d q}}{d t}+j\left(\omega_{1}-P \omega_{m e c}\right) \vec{\lambda}_{2 d q}
\end{gathered}
$$

the relationship between fluxes and currents

$$
\begin{aligned}
& \vec{\lambda}_{1 d q}=L_{1} \vec{i}_{1 d q}+L_{M} \vec{i}_{2 d q} \\
& \vec{\lambda}_{2 d q}=L_{M} \vec{i}_{1 d q}+L_{2} \vec{i}_{2 d q}
\end{aligned}
$$

The electromagnetic torque is expressed in terms of the cross-vectorial product of the stator flux and the stator current space vectors.

$$
\begin{aligned}
T_{e} & =\frac{3}{2} P \frac{L_{M}}{L_{2} L_{1} \sigma} \vec{\lambda}_{2 d q} \times \vec{\lambda}_{1 d q} \\
T_{e} & =\frac{3}{2} P \frac{L_{M}}{L_{2} L_{1} \sigma}\left|\vec{\lambda}_{2 d q}\right|\left|\vec{\lambda}_{1 d q}\right| \sin \left(\alpha_{r}-\delta\right) \\
T_{e} & =\frac{3}{2} P \frac{L_{M}}{L_{2} L_{1} \sigma}\left|\vec{\lambda}_{2 d q}\right|\left|\vec{\lambda}_{1 d q}\right| \sin (\alpha)
\end{aligned}
$$


Equation (7) shows that variations in stator flux will reflect variations on rotor flux.

Where $\delta$ and $\alpha_{r}$ are the angle of the stator flux and rotor flux space vector with respect to the direct-axis of the synchronous reference frame respectively as is shown in Fig. 1, $\alpha=\alpha_{r}-\delta$ is the angle between the stator and rotor flux space vectors, $P$ is a number of pole pairs and $\sigma=1-L_{M}^{2} /\left(L_{1} L_{2}\right)$ is the dispersion factor.

Combining equations (1), (2), (3) and (4), after some manipulations, the induction machine model can be written as a complex space state equation in the synchronous reference frame (dq) and the state variables are stator current $\vec{i}_{1 d q}=i_{1 d}+j i_{1 q}$ and stator flux $\vec{\lambda}_{1 d q}=\lambda_{1 d}+j \lambda_{1 q}$ and it is shown in equation (9).

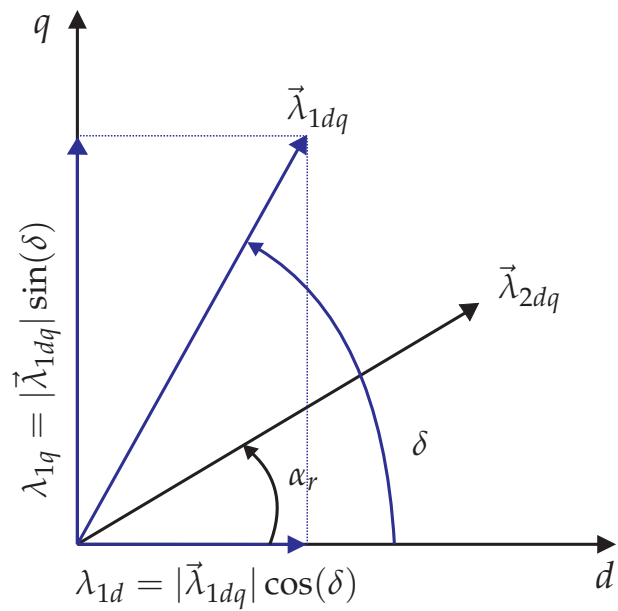

Figure 1. stator and rotor fluxes space vectors in synchronous reference frame.

$$
\begin{gathered}
\frac{d \vec{\lambda}_{1 d q}}{d t}=-j \omega_{1} \vec{\lambda}_{1 d q}-R_{1} \vec{i}_{1 d q}+\vec{v}_{1 d q} \\
\frac{d \vec{i}_{1 d q}}{d t}=a_{3} \vec{\lambda}_{1 d q}+a_{4} \vec{i}_{1 d q}+\frac{\vec{v}_{1 d q}}{\sigma L_{1}} \\
a_{3}=\left(\frac{R_{2}}{\sigma L_{1} L_{2}}-\frac{j P \omega_{m e c}}{\sigma L_{1}}\right) \\
a_{4}=-\left[\frac{R_{1}}{\sigma L_{1}}+\frac{R_{2}}{\sigma L_{2}}+j\left(\omega_{1}-P \omega_{m e c}\right)\right]
\end{gathered}
$$

The machine mechanical dynamics is given by

$$
J \frac{d \omega_{m e c}}{d t}=\frac{3}{2} P \frac{L_{M}}{L_{2} L_{1} \sigma} \vec{\lambda}_{2 d q} \times \vec{\lambda}_{1 d q}-T_{L}
$$

The $\omega_{1}$ is the synchronous speed, $\omega_{m e c}$ is the machine speed, $R_{1}$ and $R_{2}$ are the estator and rotor windings per phase electrical resistance, $L_{1}, L_{2}$ and $L_{m}$ are the proper and mutual inductances of the stator and rotor windings, $\vec{v}$ is the voltage vector,$P$ is the machine number 
of pair of poles, $J$ is the load and rotor inertia moment, the symbol "*" represents the conjugate of the complex number and $T_{L}$ is the load torque.

In order to obtain the induction motor complex transfer function the Laplace transform is applied to the equations (8) and (9) in accordance with the complex transfer function concept [24], [10]. Thus, the equation (8) complex transfer function is shown in Figure 2.

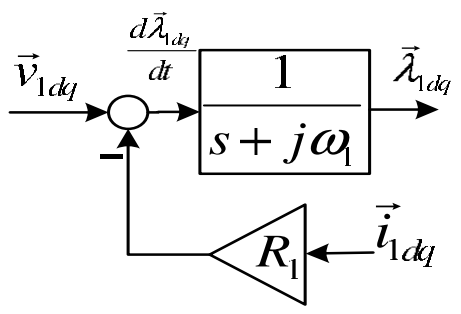

Figure 2. Equation (8) complex transfer function.

And the equation (9) complex transfer function complex transfer function is shown in Figure 3. Thus, the induction motor block diagram originated by use of the equations (8)

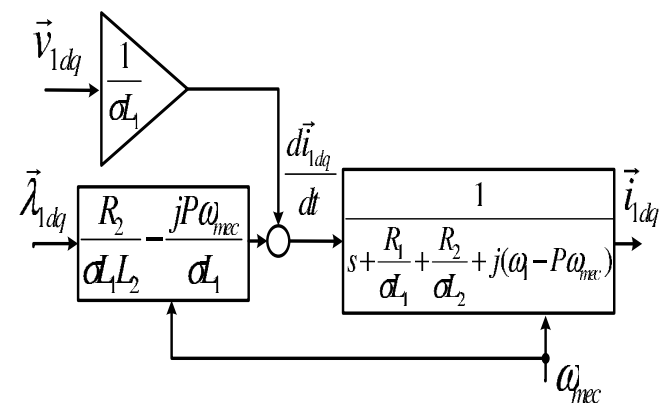

Figure 3. Equation (9) complex transfer function.

and (9) complex transfer functions shown in Figures 2 and 3 and the machine mechanical dynamics (12) is shown in Figure 4. When designing the DTC control system through the

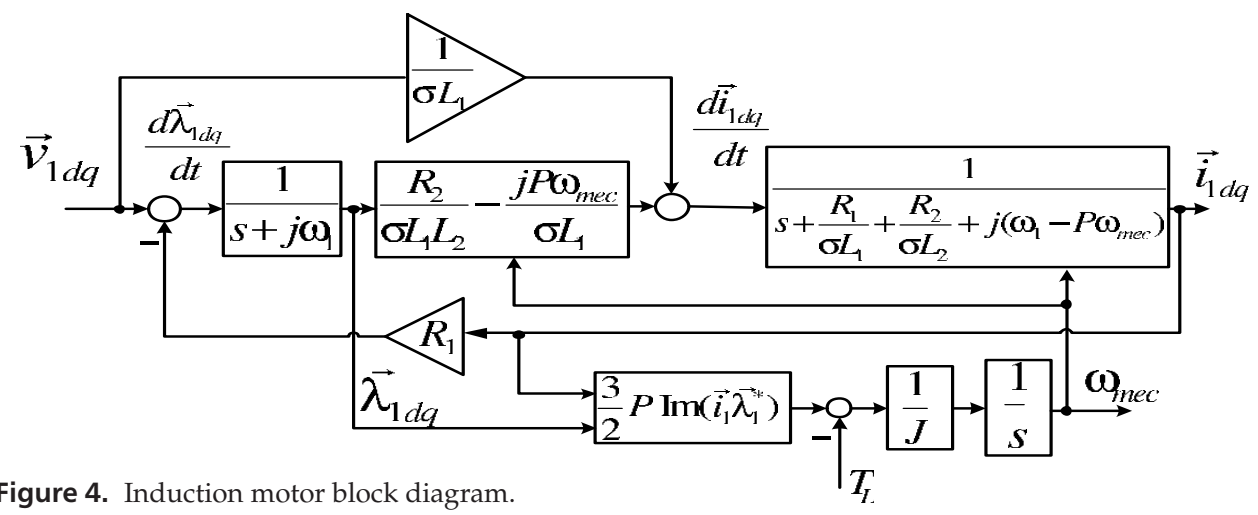


IM complex transfer function, $\vec{v}_{1 d q}$ is considered as the input and the $\vec{i}_{1 d q}$ is considered as the output. For this purpose it is assumed that the mechanical time constant of the motor is much larger than the transient electromagnetic time constants and the saturation effects is neglected. Thus, $\omega_{m e c}=$ constant is a valid approximation [24], [11]. Therefore the induction machine complex transfer function $H(s)$ is derived from application of the Laplace transform in equations (8) and (9) and it is the closed loop system of Figure 4 without machine mechanical dynamics. Thus, it has the form given in 13.

$$
H(s)=\frac{I_{1 d q}}{V_{1 d q}}=\frac{\left(\frac{s+j \omega_{1}}{\sigma L_{1}}\right)+a_{3}}{\left(s+j \omega_{1}\right)\left(s+a_{4}\right)+R_{1} a_{3}}
$$

where $I_{1 d q}=\mathcal{L}\left\{\vec{i}_{1 d q}\right\}$ and $V_{1 d q}=\mathcal{L}\left\{\vec{v}_{1 d q}\right\}$.

\section{Direct torque control}

If the sample time is short enough, such that the stator voltage space vector is imposed to the motor keeping the stator flux constant at the reference value. The rotor flux will become constant because it changes slower than the stator flux.

The electromagnetic torque (14) can be quickly changed by changing the angle $\alpha$ in the desired direction. The angle $\alpha$ can be easily changed when choosing the appropriate stator voltage space vector.

$$
T_{e}=\frac{3}{2} P \frac{L_{M}}{L_{2} L_{1} \sigma}\left|\vec{\lambda}_{2 \alpha \beta}\right|\left|\vec{\lambda}_{1 \alpha \beta}\right| \sin (\alpha)
$$

For simplicity, let us assume that the stator phase ohmic drop could be neglected in $\vec{v}_{1 \alpha \beta}=$ $R_{1} \vec{i}_{1 \alpha \beta}+\frac{d \vec{\lambda}_{1 \alpha \beta}}{d t}$. Therefore $d \vec{\lambda}_{1 \alpha \beta} / d t=\vec{v}_{1 \alpha \beta}$. During a short time $\Delta t$, when the voltage space vector is applied it has:

$$
\Delta \vec{\lambda}_{1 \alpha \beta} \approx \vec{v}_{1 \alpha \beta} \cdot \Delta t
$$

Thus, the stator flux space vector moves by $\Delta \vec{\lambda}_{1 \alpha \beta}$ in the direction of the stator voltage space vector at a speed which is proportional to the magnitude of the stator voltage space vector. By selecting step-by-step the appropriate stator voltage vector, it is possible to change the stator flux in the required direction.

\subsection{Stator flux oriented direct torque control}

The stator flux oriented direct torque control (SFO-DTC) have two PI regulators. The outputs of the PI flux and torque controllers can be interpreted as the stator voltage components in the stator flux oriented coordinates as shown in Fig. 5 [23], [3]. The control strategy relies on a simplified description of the stator voltage components, expressed in stator-flux-oriented coordinates as:

$$
\begin{gathered}
v_{1 d}=R_{1} i_{1 d}+\frac{d \lambda_{1}}{d t} \\
v_{1 q}=R_{1} i_{1 q}+\omega_{1} \lambda_{1}
\end{gathered}
$$


Where $\omega_{1}$ is the angular speed of the stator flux vector. The above equations show that the component $v_{1 d}$ has influence only on the change of stator flux magnitude, and the component $v_{1 q}$, if the term $\omega_{1} \lambda_{1}$ is decoupled, can be used for torque adjustment. Therefore, after coordinate transformation $d q / \alpha \beta$ into the stationary frame, the command values $v_{1 d_{r e f}}, v_{1 q_{r e f}}$, are delivered to SVM module.

This SFO-DTC scheme requires the flux and the torque estimators, which can be performed as it is proposed in Fig. 5. Therefore, the control signals are fed to the power electronics drive.

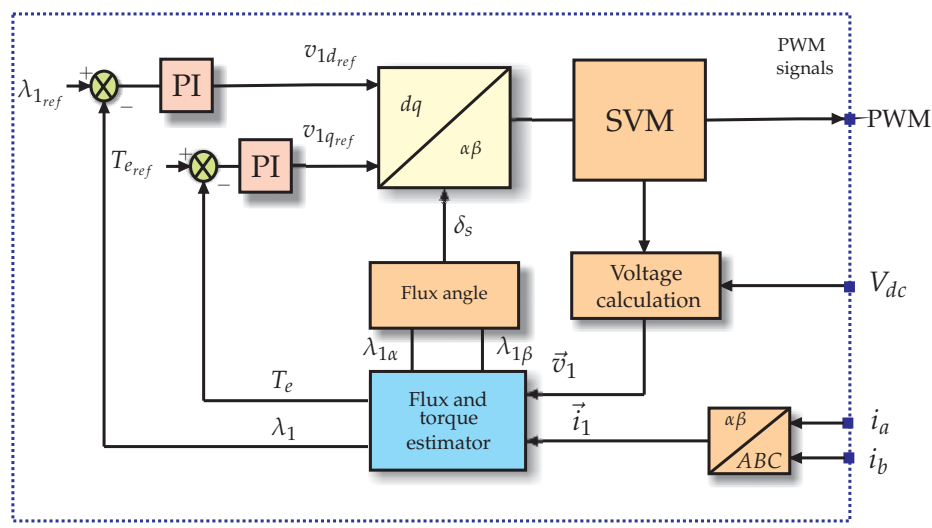

Figure 5. Stator flux oriented direct torque control scheme.

\section{Design and tuning PI gains}

By using stator field orientation, the torque and stator flux must become parts of a complex number, where the magnitude of the stator flux $\lambda_{1}$ is the real component and the torque $T_{e}$ is the imaginary component. Hence, the reference signals and the error become a complex number. Thus, the PI regulators presented in the before section [23] has the function to generate a voltage reference space vector using the stator flux-torque error vector $\left(\varepsilon_{\lambda}+j \varepsilon_{T}\right)$. This way the stator-voltage vector in this control strategy is given by

$$
\vec{v}_{1 d q_{r e f}}=\left(\varepsilon_{\lambda}+j \varepsilon_{T}\right)\left(K p+\frac{K i}{s}\right)
$$

Which means that the direct and quadrature axis of the voltage vector are

$$
\begin{aligned}
& v_{1 d_{\text {ref }}}=\left(\varepsilon_{\lambda}\right)\left(K p+\frac{K i}{s}\right) \\
& v_{1 q_{\text {ref }}}=\left(\varepsilon_{T}\right)\left(K p+\frac{K i}{s}\right)
\end{aligned}
$$

Where $k p$ is the proportional gain, $k i$ is the integral gain, $\varepsilon_{\lambda}$ is the flux error signal and $\varepsilon_{T}$ is the torque error signal.

The block diagram of the strategy with the PI regulators is shown in Figure 6. 
The reference stator voltage vector $\vec{v}_{1 d q_{\text {ref }}}$ is transformed by using stator flux angle $\delta_{s}$ to obtain the stator voltage at stationary reference frame $\alpha \beta$.

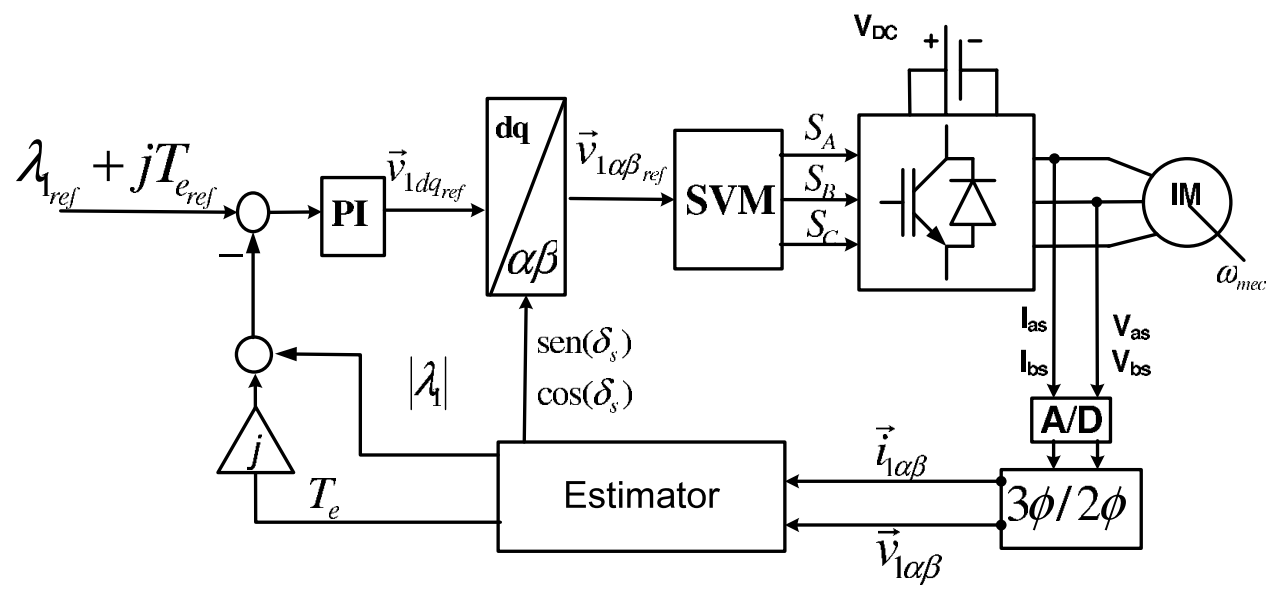

Figure 6. DTC strategy with PI regulators and complex signals.

\subsection{Stator flux estimation}

The stator flux estimation is done by

$$
\vec{\lambda}_{1 \alpha \beta}=\int\left(\vec{v}_{1 \alpha \beta}-R_{1} \vec{i}_{1 \alpha \beta}\right) d t
$$

A satisfactory flux estimation for induction motor at low speed using Equation (21) is obtained by using the integration method presented in [8] and the block diagram for the flux stimation is presented in Figure 7

The stator flux angle is estimated by using the trigonometric transfer function

$$
\delta_{s}=\arctan \left(\frac{\lambda_{1 \beta}}{\lambda_{1 \alpha}}\right)
$$

\subsection{Design of the PI regulator gains}

In order to tune the PI regulator it is necessary the closed-loop complex transfer function of the controlled induction motor. The complex transfer function of the controlled induction motor was also used to tune a complex gain controller in which has been presented in [7].

In accordance with the DTC control strategy the induction motor output has to be the stator flux magnitude $\lambda_{1}$ and the torque $T_{e}$. Therefore the H(s) (13) outputs have to become the stator flux magnitude $\lambda_{1}$ and the torque $T_{e}$. The expression to obtain the stator flux by using the stator current $i_{1 d}$ is given by

$$
\lambda_{1}=\lambda_{1 d} \cong G \sigma L_{1} i_{1 d}
$$




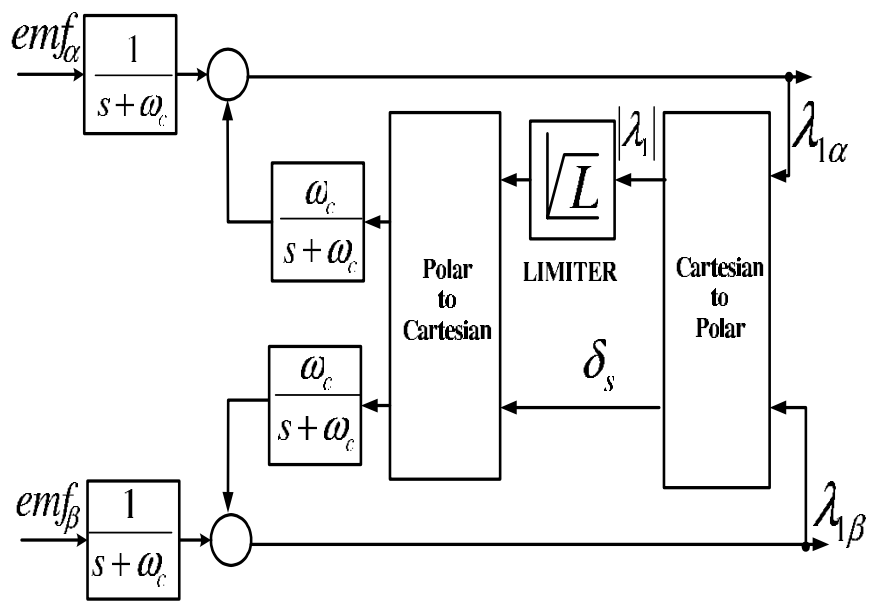

Figure 7. Block diagram for the stator flux stimation.

and to obtain the electromagnetic torque in the $d q$ reference frame one may use the expression:

$$
T_{e}=\frac{3}{2} P \lambda_{1} i_{1 q}
$$

As the stator flux magnitude $\lambda_{1}$ is assumed to be essentially constant through of the equations (13), (23) and (24) the new transfer function is achieved with torque and flux as output and it is given by

$$
\frac{X_{\lambda T}}{V_{1 d q}}=H(s)\left(G \sigma L_{1}+j P \frac{3}{2} \lambda_{1}\right)
$$

where $X_{\lambda T}=\mathcal{L}\left\{\lambda_{1}+j T_{e}\right\}$.

The low speeds utilized in this book chapter are $60 \mathrm{rpm}(6.25 \mathrm{rad} / \mathrm{s}), 125 \mathrm{rpm}(13 \mathrm{rad} / \mathrm{s}), 150$ $\mathrm{rpm}(16 \mathrm{rad} / \mathrm{s}), 180 \mathrm{rpm}(17 \mathrm{rad} / \mathrm{s})$ that corresponds to $2 \mathrm{~Hz}, 4.16 \mathrm{~Hz}, 5 \mathrm{~Hz}$ and $6 \mathrm{~Hz}$ respectively. The frequency-response function of Equation (25) is presented in Figure 8 at frequencies $2 \mathrm{~Hz}$, $4.16 \mathrm{~Hz}, 5 \mathrm{~Hz}$ and $6 \mathrm{~Hz}$ in accordance with the induction motor desired speed.

Then, from Equations (18) and (25) one obtain the control system block diagram and it is shown in Figure 9.

The expression of the closed loop transfer function of the system to design the PI regulators showed in Figure 9 is given by

$$
\frac{X_{\lambda T}}{X_{\lambda T_{r e f}}}=\frac{\left(K p+\frac{K i}{s}\right) H(s)\left(G \sigma L_{1}+j P \frac{3}{2} \lambda_{1}\right)}{1+\left(K p+\frac{K i}{s}\right) H(s)\left(G \sigma L_{1}+j P \frac{3}{2} \lambda_{1}\right)}
$$

where $X_{\lambda T_{r e f}}=\mathcal{L}\left\{\lambda_{1_{\text {ref }}}+j T_{e_{\text {ref }}}\right\}$. 


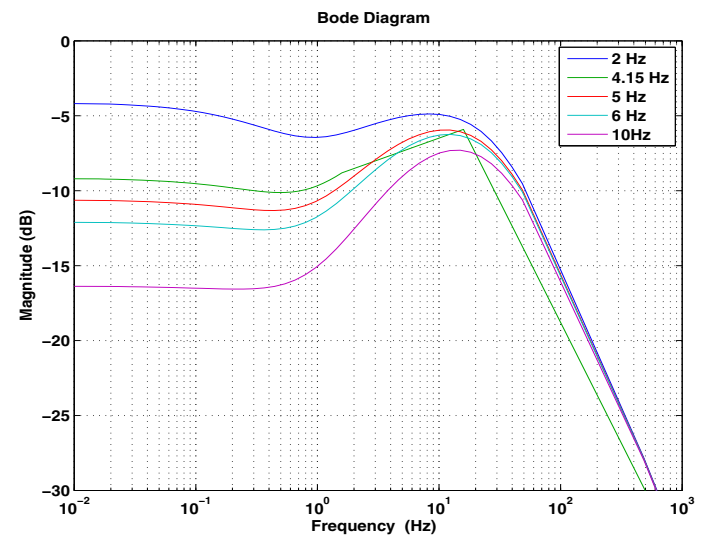

Figure 8. Equation (25) frequency-response function.

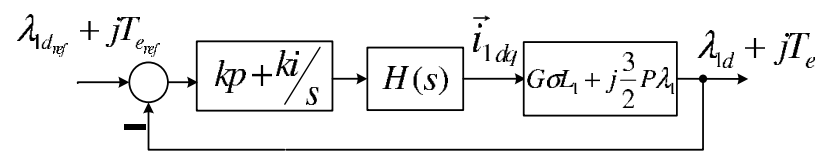

Figure 9. System to design the PI regulator.

As the variables at synchronous referential are constants the angle of output $X_{\lambda T}$ is neglected. At the frequency of $2 \mathrm{~Hz}, 4.16 \mathrm{~Hz}$ and $6 \mathrm{~Hz}$ the $k p$ and $k i$ gains are chosen by using simulations, considering slip approximately null and the $0 \mathrm{~dB}$ magnitude. Them values are $k p=155$ and $k i=15$. The frequency-response function of Equation (26) is shown in Figure 10 and its magnitude is near $0 \mathrm{~dB}$.

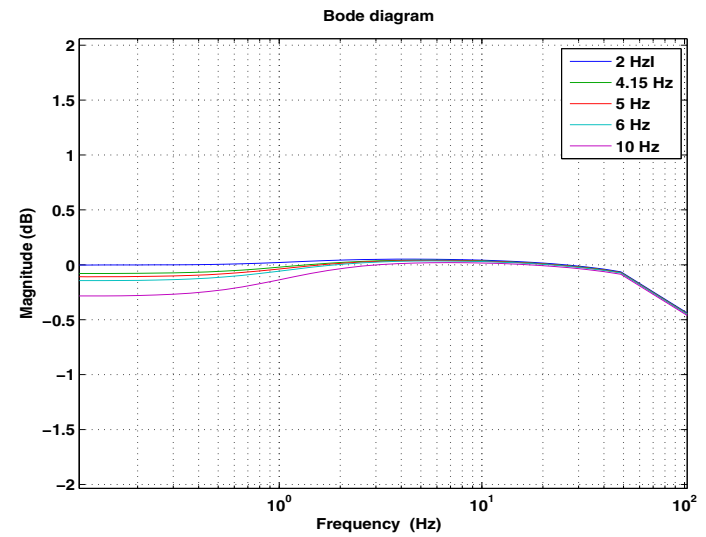

Figure 10. Frequency-response function of the equation (26) 


\section{Experimental results}

The DTC strategy were implemented using a Texas Instruments DSP TMS320F2812 platform. The system consists of a three-phase voltage source inverter with insulated-gate bipolar transistors (IGBTs) and the three-phase induction motor parameters are shown in the appendix. The stator voltage commands are modulated by using symmetrical space vector PWM, with switching frequency equal to $2.5 \mathrm{kHz}$. The DC bus voltage of the inverter is $226 \mathrm{~V}$. The stator voltages and currents are sampled in the frequency of $2.5 \mathrm{kHz}$. A conventional PI regulators generates a torque reference by using the speed error. The flux and torque estimation, and the flux and torque PIs regulators and speed controller have the same sampling frequency of $2.5 \mathrm{kHz}$. The encoder resolution is 1500 pulses per revolution. The algorithm of the DTC strategy was programmed on the Event Manager 1 of the Texas Instruments DSP TMS320F2812 platform and its flowchart is presented in Figure 11 and the schematic of implemention is presented in Figure 12.

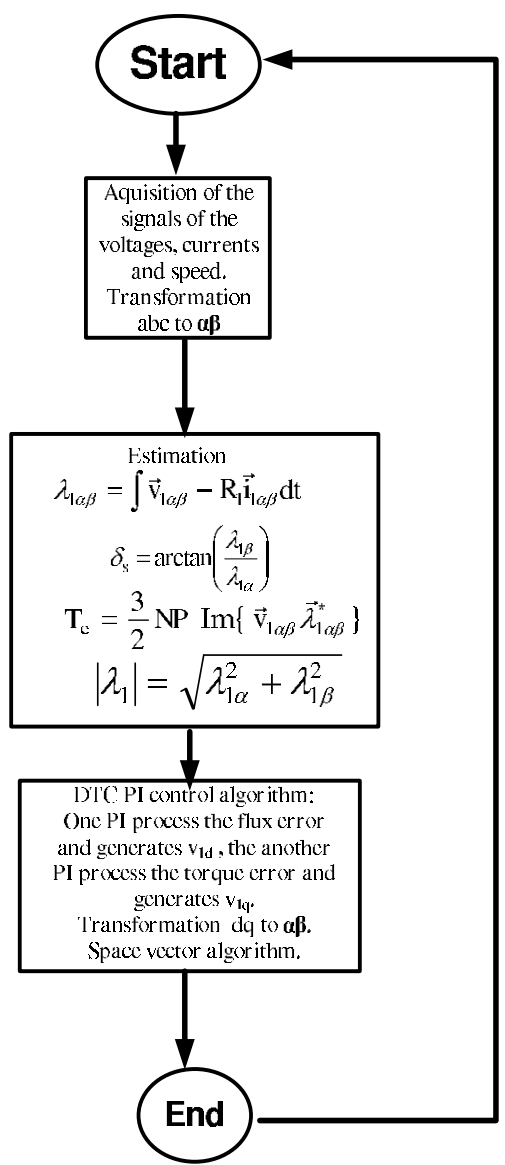

Figure 11. The flowchart of the DSP program. 


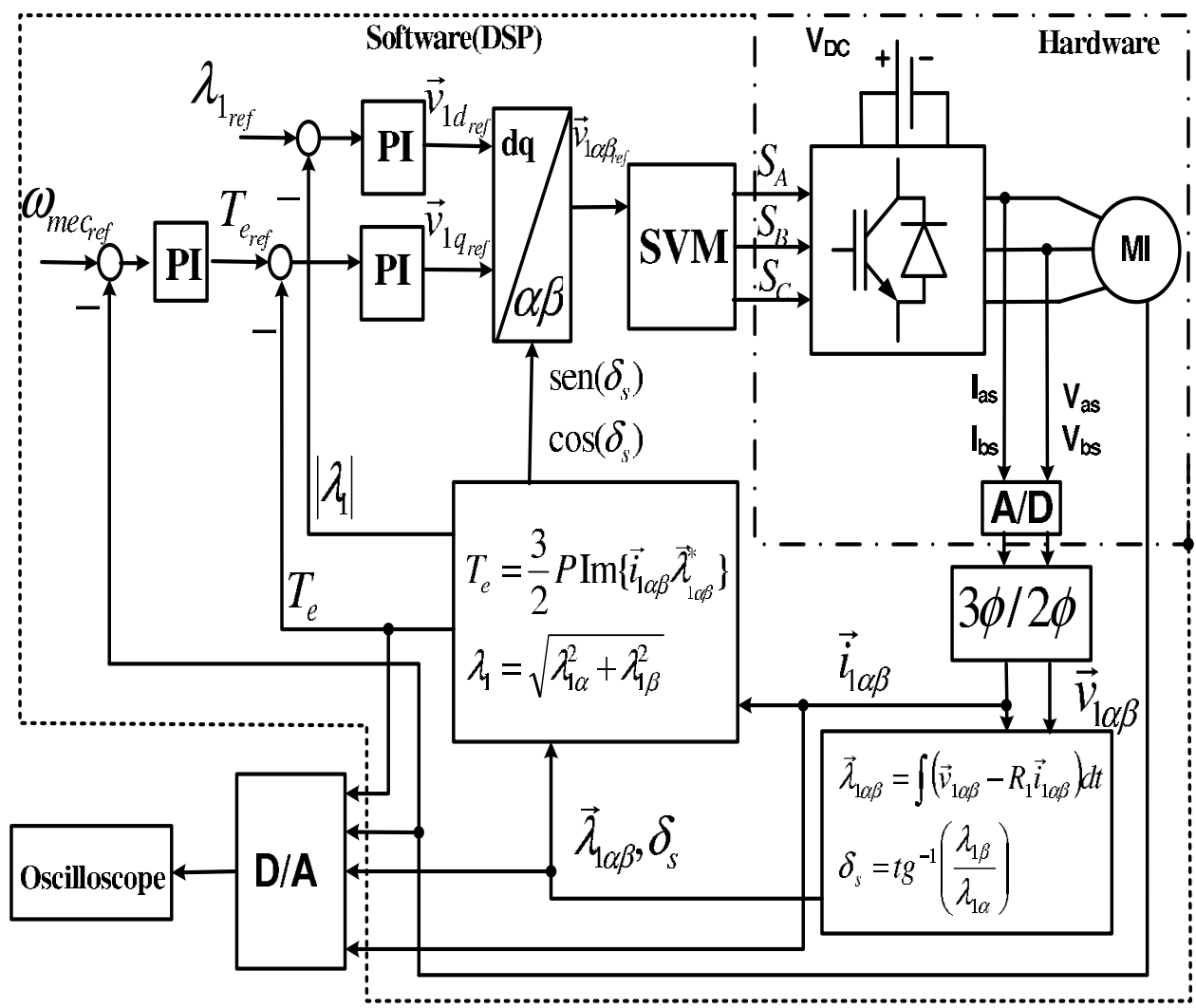

Figure 12. Schematic of implemention.

Five no-load induction motor tests were made. The first one was the response to a torque step of $12.2 \mathrm{Nm}$ which is shown in Figure 13. It can be seen the satisfactory response of torque although it has oscillation. This oscillation occurs due to the natural lack of accuracy in the measurements of currents, voltages and parameters variations.

Figure 14 shows when the speed varies from $6.28 \mathrm{rad} / \mathrm{s}$ to $18.85 \mathrm{rad} / \mathrm{s}$ in $200 \mathrm{~ms}$. This result confirms the satisfactory performance of the controller due to the fact that the the speed reaches the reference in several conditions although the gains of PI are designed for induction motor speed operation at $2 \mathrm{~Hz}$ and $6 \mathrm{~Hz}$.

In the third test the speed varies in forward and reversal operation and the result are presented in Figures 15(a) and 15(b). The speed changes from $13 \mathrm{rad} / \mathrm{s}$ to $-13 \mathrm{rad} / \mathrm{s}$ in $1 \mathrm{~s}$ and the gains of PI regulator are not changed during the test. This result confirms the satisfactory performance of the controller due to the fact that the the speed reaches the reference in several conditions and the PI regulator was designed for induction motor speed operation at $4.15 \mathrm{~Hz}$. The small error occurs due the natural lack of accuracy in the measurement of the speed.

Figure 16 presents the speed response when the speed varies from $6.28 \mathrm{rad} / \mathrm{s}$ to $-6.28 \mathrm{rad} / \mathrm{s}$. The result confirms the satisfactory performance of the PI regulator again due to the fact that 


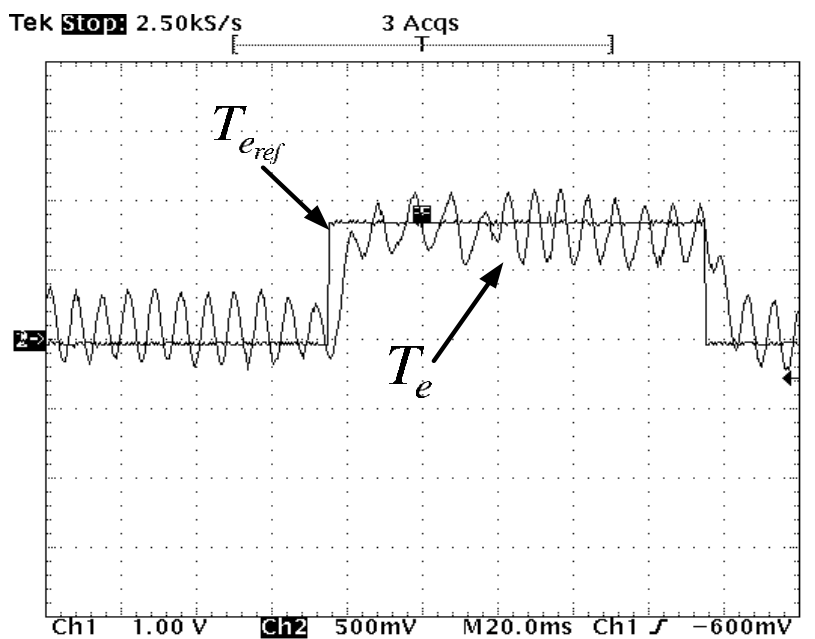

Figure 13. Responses to step torque operation ( $9 \mathrm{Nm} / \mathrm{div})$.

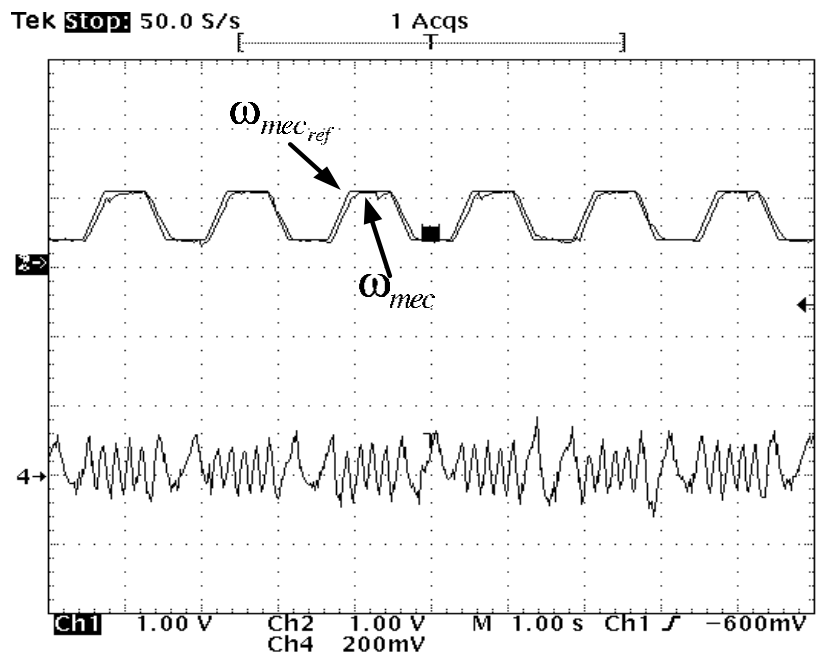

Figure 14. Speed forward and reversal operation (15.7 ras/s.div) and $a$ phase current (10 A/div).

the speed reaches the reference value and the gains of PI are designed for induction motor speed operation at $2 \mathrm{~Hz}$.

In load test the speed reference was $36.6 \mathrm{rad} / \mathrm{s}$ and a load torque of $11.25 \mathrm{~N} . \mathrm{m}$ was applied to the motor. In this test a dc generator is coupled to the rotor of induction motor. So the generated voltage of the DC generator is conected to the load with variable resistance. The test is shown in Figure 17 and the steady state error is $4.5 \%$. 


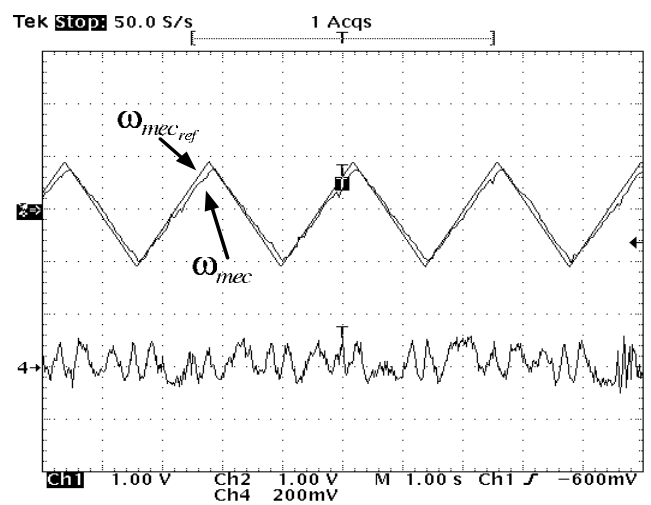

(a) Speed reversal operation (12.57 rad/s.div).

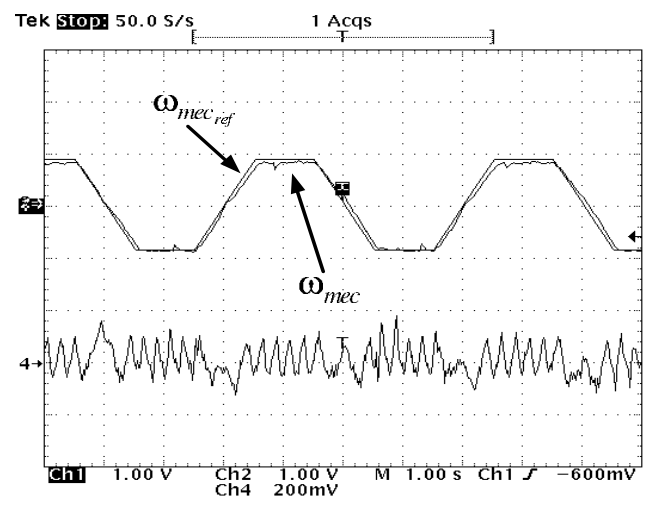

(b) Speed forward and reversal (13 rad/s.div).

Figure 15. Speed forward and reversal operation and $a$ phase current $(10 \mathrm{~A} / \mathrm{div})$

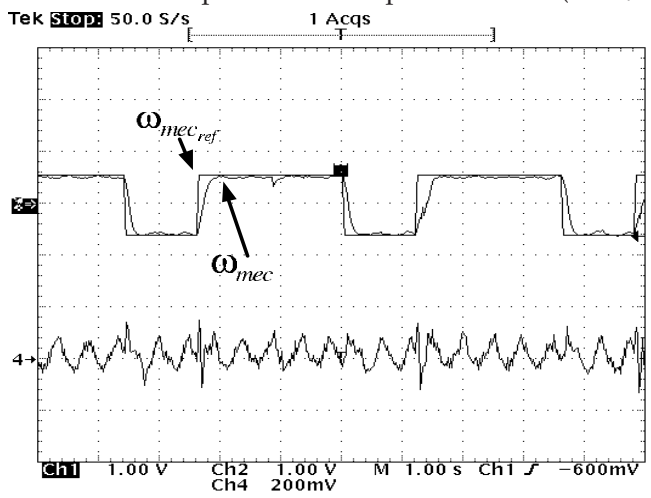

Figure 16. Speed response to step operation (12.57 rad/s.div) and a phase current (10 A/div). 


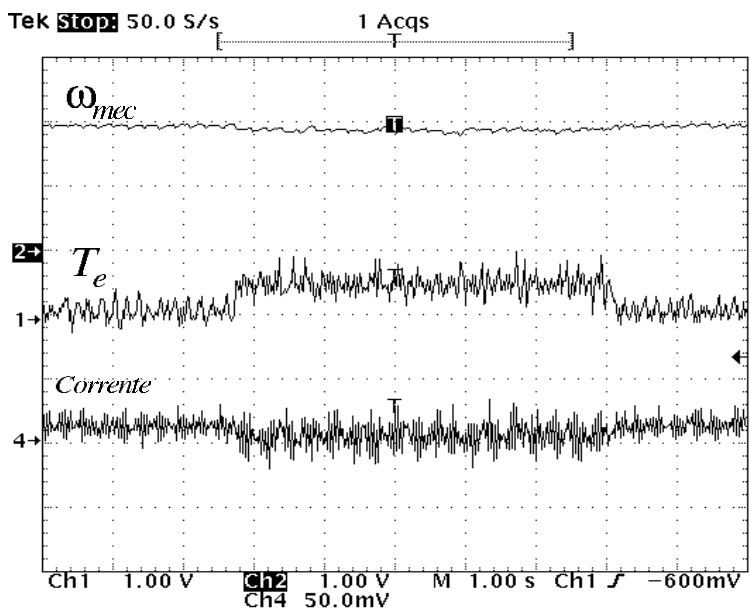

Figure 17. Load test (18,3 rad/s.div) and a phase current (20 A/div).

\section{Conclusion}

In this book chapter was presented a method to design and tune the PI regulators for the three-phase IM DTC-SVM strategy using the mathematical model complex transfer function when the machine operates at low speed. The concept of complex transfer function allows to obtain the PI regulator gains by using the closed loop system frequency response function of the controlled induction motor.

The experimental results shown the satisfactory performance of the regulator due to the fact that the speed reaches the reference value in several conditions although the complex gain was designed for a limited points of induction motor operation. Thus, the design of PI regulator has an acceptable performance although an detailed analysis considering parameters variations and other several speed operations has to be done. Due to the variable speed operation maybe it will be necessary to construct a table with PI gains designed for each desired speed or to an each speed range. The PI regulator overcomes the low speed operations shortcomings to the IM DTC-SVM strategy with a minor complexity. Thus, the complex transfer function becomes an interesting tool for design and tune PI regulator for IM drives.

\section{Appendix}

Three-phase induction motor variables and parameters: $P N=2.3 \mathrm{~kW} ; V_{N}=220 \mathrm{~V}$; Poles $=4$ $R_{1}=2.229 \Omega ; R_{2}=1.522 \Omega ; L_{m}=0.238485 H ; L_{1}=0.2470 H ; L_{2}=0.2497 H ; J=0.0067$ $\mathrm{Kgm}^{2}$.

\section{Acknowledgment}

The authors are grateful to CAPES, CNPq and FAPESP for the financial support for this research. 


\section{Author details}

Alfeu J. Sguarezi Filho

Universidade Federal do $A B C$, Brazil

José Luis Azcue and Ernesto Ruppert

School of Electrical and Computer Engineering, University of Campinas, Brazil

\section{References}

[1] Blaschke, F. [1977]. The principle of field orientation control as applied to the new transvector closed loop control system for rotating machines, Siemens Review 39(5): 217-220.

[2] Briz, F., degener, M. W. \& Lorenz, R. D. [2000]. Analysis and design of current regulators using complex vectors, IEEE Trans. Ind. Applicat. 32: 817-825.

[3] Buja, G. \& Kazmierkowski, M. [2004]. Direct torque control of pwm inverter-fed ac motors - a survey, Industrial Electronics, IEEE Transactions on 51(4): 744-757.

[4] Cad, M. M. \& de Aguiar, M. L. [2000]. The concept of complex transfer functions applied to the modeling of induction motors, IEEE Winter Meeting 2000 of the IEEE Power Engineering Society .

[5] Casadei, D., Serra, G. \& Tani, A. [2001]. Steady-state and transient performance evaluation of a dtc scheme in the low speed range, IEEE Trans. on Power Electronics 16(6): 846-851.

[6] Depenbrock, M. [1988]. Direct self-control(dsc) of inverter-fed induction machine, IEEE Trans. Power Electronics 3(4): 420-429.

[7] Filho, A. J. S. \& Filho, E. R. [2008]. The complex controller applied to the induction motor control, IEEE Applied Power Electronics Conference and Exposition - APEC pp. 1791-1795.

[8] Filho, A. J. S. \& Filho, E. R. [2009]. The complex controller for three-phase induction motor direct torque control, Sba Controle e Automação 20(2).

[9] Gataric, S. \& Garrigan, N. R. [1999]. Modeling and design of three-phase systems using complex transfer functions, IEEE Trans. Ind. Electron. 42: 263-271.

[10] Holtz, J. [1995]. The representation of ac machine dynamics by complex signal flow graphs, IEEE Trans. Ind. Electron. 42: 263-271.

[11] Holtz, J., Quan, J., Pontt, J., Rodríguez, J., newman, P. \& Miranda, H. [2004]. Design of fast and robust current regulators for high-power drives based on complex state variables, IEEE Trans. Ind. Applications 40: 1388-1397.

[12] Kenny, B. H. \& Lorenz, R. D. [2001]. Stator and rotor flux based deadbeat direct torque control ofinduction machines, IEEE Industry Applications Conference 1: 133-139.

[13] Kovács, P. K. \& Rácz, E. [1984]. Transient Phenomena in Electrical Machines, Amsterdam, The Netherlands: Elsevier.

[14] Kumsuwana, Y., Premrudeepreechacharna, S. \& Toliyat, H. A. [2008]. Modified direct torque control method for induction motor drives based on amplitude and angle control of stator flux, Electric Power Systems Research 78: 1712-1718.

[15] Lee, K.-B., Blaabjerg, F. \& Yoon, T.-W. [2007]. Speed-sensorless dtc-svm for matrix converter drives with simple nonlinearity compensation, IEEE Transactions on Industry Applications 43(6): 1639-1649. 
[16] Leonhard, W. [1985]. Control of Electrical Drives, Springer-Verlag Berlin Heidelberg New York Tokyo.

[17] Novotny, D. W. \& Lipo, T. A. [1996]. Vector Control and Dynamics of AC Drives, Clarendon Press OXFORD.

[18] Phillips, C. [2000]. Feedback Control Systems, Pretince Hall.

[19] Ryu, J. H., Lee, K. W. \& Lee, J. S. [2006]. A unified flux and torque control method for dtc-based induction-motor drives, IEEE Trans. on Power Electronics 21(1): 234-242.

[20] Shady M. Gadoue, D. G. \& Finch, J. W. [2005]. Tuning of pi speed controller in dtc of induction motor based on genetic algorithms and fuzzy logic schemes, International Conference on Technology and Automation .

[21] Sheu, T.-T. \& Chen, T.-C. [1999]. Self-tuning control of induction motor drive using neural network identifier, IEEE Transactions on Energy Conversion 14(4).

[22] Takahashi, I. \& Noguchi, T. [1986]. A new quick-response and high-efficiency control strategy of an induction motor, Industry Applications, IEEE Transactions on IA-22(5): 820 $-827$.

[23] Xue, Y., Xu, X., Habetler, T. G. \& Divan, D. M. [1990]. A low cost stator flux oriented voltage source variable speed drive, Conference Record of the 1990 IEEE Industrial Aplications Society Annual Meetting 1: 410-415.

[24] Yamamura, S. [1992]. Spiral Vector Theory of AC Circuits and Machines, Clarendon Press OXFORD. 